\title{
Effects of the Molecular Weight and the Degree of Deacetylation of Chitosan Oligosaccharides on Antitumor Activity
}

\author{
Jae Kweon Park ${ }^{\dagger}$, Mi Ja Chung ${ }^{\dagger}$, Ha Na Choi and Yong Il Park* \\ Department of Biotechnology, The Catholic University of Korea, Bucheon, Gyeonggi-do 420-743, \\ Korea; E-Mails: jamyeong@yahoo.co.kr (J.K.P.); mimichung@ hanmail.net (M.J.C.); \\ glitter_hana@naver.com (H.N.C.)
}

$\dagger$ These authors contributed equally to this work.

* Author to whom correspondence should be addressed; E-Mail: yongil382@ catholic.ac.kr;

Tel.: +82-2-2164-4512; Fax: +82-2-2164-4846.

Received: 26 November 2010; in revised form: 3 January 2011 / Accepted: 4 January 2011 / Published: 6 January 2011

\begin{abstract}
Effects of the degree of deacetylation (DDA) and the molecular mass of chitosan oligosaccharides (CTS-OS), obtained from the enzymatic hydrolysis of high molecular weight chitosan (HMWC), on antitumor activity was explored. The DDA and molecular weights of CTS-OS were determined by matrix-assisted laser desorption/ionization-mass spectrometry (MALDI-TOF MS) analysis. The CTS-OS were found to be a mixture of mainly dimers (18.8\%), trimers $(24.8 \%)$, tetramers $(24.9 \%)$, pentamers $(17.7 \%)$, hexamers $(7.1 \%)$, heptamers $(3.3 \%)$, and octamers $(3.4 \%)$. The CTS-OS were further fractionated by gel-filtration chromatography into two major fractions: (1) COS, consisting of glucosamine $(\mathrm{GlcN})_{\mathrm{n}}, \mathrm{n}=3-5$ with DDA $100 \%$; and (2) HOS, consisting of $(\mathrm{GlcN})_{5}$ as the minimum residues and varying number of $N$-acetylglucosamine $(\mathrm{GlcNAc})_{\mathrm{n}}, \mathrm{n}=1-2$ with DDA about $87.5 \%$ in random order. The cytotoxicities, expressed as the concentration needed for $50 \%$ cell death $\left(\mathrm{CC}_{50}\right)$, of CTS-OS, COS, and HOS against PC3 (prostate cancer cell), A549 (lung cancer cell), and HepG2 (hepatoma cell), were determined to be $25 \mu \mathrm{g} \cdot \mathrm{mL}^{-1}, 25 \mu \mathrm{g} \cdot \mathrm{mL}^{-1}$, and $50 \mu \mathrm{g} \cdot \mathrm{mL}^{-1}$, respectively. The HMWC was approximately $50 \%$ less effective than both CTS-OS and COS. These results demonstrate that the molecular weight and DDA of chitosan oligosaccharides are important factors for suppressing cancer cell growth.
\end{abstract}


Keywords: chitosan oligosaccharides; antitumor activity; MALDI-TOF MS; molecular weight; degree of deacetylation

\section{Introduction}

Chitin is the second most abundant naturally occurred homopolysaccharide composed of $\beta$-(1,4)-linked-D- $N$-acetylglucosamine (GlcNAc) after cellulose. Chitosan is a linear heteropolysaccharide composed of $\beta$-(1,4)-linked-D-glucosamine $(\mathrm{GlcN})$ and $N$-acetylglucosamine (GlcNAc), which is derived from chitin. For several decades, the study on chitosan has attracted interest in converting it into more soluble form of chitosan-oligosaccharides, hereafter referred to CTS-OS, which exhibit remarkable biological activities [1-5]; they are non-toxic, biocompatible and biodegradable [6], including antibacterial antifungal, antitumor and stimulating immunoenhancing properties. It is implicated that the biological activities of CTS-OS significantly depend on their molecular weight and the degree of deacetylation (DDA) of the parental material chitosan. This is affected by the distribution pattern of GlcN/GlcNAc along the oligomeric chain of CTS-OS [7-9]. In order to study the relationship between structure and biological activity, structurally well-defined CTS-OS represent important factors to provide information regarding the development of enzymatic process with different enzymes that have different substrate specificity or cleavage patterns.

There have been numerous reports studying the antitumor activity of chitosan and its derivatives which are chemically modified [10-14]. Among them, it is known that the antitumor mechanism of chitosan nanoparticles is related to its membrane-disrupting and apoptosis-inducing activities [15,16]. However antitumor mechanism of CTS-OS with different molecular weights and DDA are not well studied yet. Although it was suggested that lower molecular weight chitosan or water-soluble chitosan may have antitumor activities in clinical use, such effects of them-including of CTS-OS having different molecular weights and DDA - are as yet unproven. Therefore, structurally well-defined CTS-OS would represent important tools for investigating the antitumor effect of CTS-OS.

In this study, we have attempted to develop a simple strategy for the preparation of more soluble forms of chitosan-oligosaccharides (CTS-OS) from the high-molecular weight chitosan (HMWC) and have investigated their structure and biological activities, especially on several tumor cell lines. For this purpose, CTS-OS were prepared by enzymatic digestion of HMWC and the relationship between their structures (molecular weights and DDA) and antitumor activities was examined against human PC3 (prostate cancer cell), human A549 (carcinomic human alveolar basal epithelial cell), and human HepG2 (hepatomacellular carcinoma) cells.

\section{Results and Discussion}

\subsection{Gel-Filtration Chromatography of Chitosan Oligosaccharides}

The chitosan-oligosaccharides (CTS-OS) in the supernatant after hydrolysis of HMWC with a chitosanase were recovered and lyophilized by the method described in the Materials and Methods to seek the feasibility of CTS-OS for the test of antitumor efficacy. CTS-OS was separated using an 
ultrafiltration membrane filter with a molecular weight cut off (MWCO) of $10 \mathrm{kDa}$. The major product of CTS-OS was yielded at about $95 \pm 0.05 \%$ after freeze drying. The major component of CTS-OS was found to be composed of, with different levels of DDA, dimer (18.8\%), trimer $(24.8 \%)$, tetramer $(24.9 \%)$, pentamer $(17.7 \%)$, hexamer $(7.1 \%)$, heptamer $(3.3 \%)$, and octamer $(3.4 \%)$ (Table 1$)$.

Table 1. Preparation of chitosan oligosaccharides.

\begin{tabular}{ccc}
\hline Chitosan oligosaccharides & Yields $(\boldsymbol{\%}) *$ & DDA $(\boldsymbol{\%}) * *$ \\
\hline Dimer & 18.8 & 100 \\
Trimer & 24.8 & 100 \\
Tetramer & 24.9 & 100 \\
Pentamer & 17.7 & 100 \\
Hexamer & 7.1 & 833.3 \\
Heptamer & 3.3 & 85.7 \\
Octamer & 3.4 & 87.5 \\
\hline
\end{tabular}

* The production yields of each oligosaccharide obtained by enzymatic hydrolysis of chitosan were calculated based on MALDI-TOF MS analysis data.

** DDA, degree of deacetylation of chitosan oligosaccharides.

These results showed that the major component of CTS-OS derived from the enzymatic digestion of chitosan was identified to be $(\mathrm{GlcN})_{\mathrm{n}}, \mathrm{n}=2-5$, with yields of about $86 \pm 0.2 \%$ after the freeze drying. CTS-OS was further then fractionated using a gel-filtration column chromatography (Figure 1). The carbohydrate positive fractions denoted F-1 (fractions 5-9) and F-2 (fraction 10-14) were pooled, dialyzed and freeze-dried. The two major carbohydrate-positive fractions obtained were applied to MALDI-TOF MS analysis, after which they were tentatively named chito-oligosaccharides (COS) and hetero-oligosaccharides (HOS). As shown in Table 1, DDA of CTS-OS obtained after the gel-filtration was determined to be in the range between 83.3 to $100 \%$. Of these, COS was recovered over $86 \%$ from CTS-OS as fully deacetylated oligosaccharides by the gel-filtration column chromatography, which was shown to be a good approach for the separation of COS and HOS from CTS-OS with different DDA and molecular weights derived from the HMWC.

Figure 1. Gel-filtration column chromatography of chitosan oligosaccharides (CTS-OS). CTS-OS were fractionated through a Bio P-4 gel-filtration column at ambient temperature. F-1, fractions 5-9; F-2, fractions 10-14.

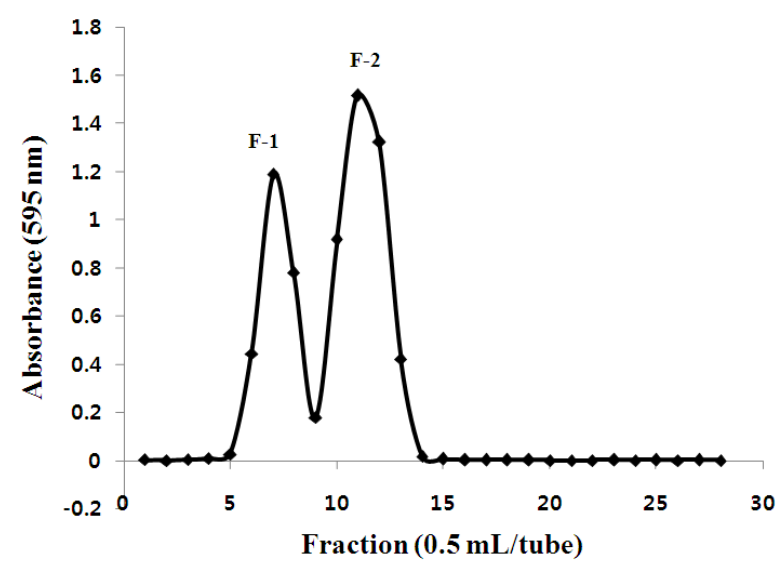




\subsection{MALDI-TOF MS Analysis}

Since the molecular weight and the degree of $N$-deacetylation of chitosan appeared to be key factors in such biological activity, MALDI-TOF MS analysis was conducted to determine the molecular weight and primary structure of F-1 and F-2. MALDI-TOF MS analysis showed that F-1 consisted of a mixture of $(\mathrm{HOS})_{\mathrm{n}}, \mathrm{n}=6-15$ (Figure $2 \mathrm{~A}$ ), while $\mathrm{F}-2$ consisted of a mixture of $(\mathrm{COS})_{\mathrm{n}}, \mathrm{n}=3-5$ (Figure 2B). F-2 contained about $67 \%(\mathrm{COS})_{\mathrm{n}}, \mathrm{n}=3-5$ when compared to the relative percent intensity of the results obtained from the MALDI-TOF MS analysis of CTS-OS (Table 1). On the other hand, $(\mathrm{HOS})_{\mathrm{n}}, \mathrm{n}=6-15$ in F-1, which was detected in much lower quantity than $(\mathrm{COS})_{\mathrm{n}}, \mathrm{n}=3-5$ (Table 1), was obviously concentrated by Bio P-4 gel-filtration chromatography (Figure 2A). (COS) 2 could not be separated through Bio P-4 gel filtration chromatography. The existence of different components of oligosaccharides consisting of GlcN and GlcNAc in random order in CTS-OS indicated that the parental HMWC is partially deacetylated chitosan. Nevertheless, as shown in Figure $2 \mathrm{~B},(\mathrm{COS})_{\mathrm{n}}$, $\mathrm{n}=3-5$ in F-2 obtained from the gel filtration chromatography was the major component of the mixture of CTS-OS.

Figure 2. Determination of the molecular mass and the degree of deacetylation of chitosan oligosaccharides. The chitosan oligosaccharides, F-1 (A) and F-2 (B), obtained after enzymatic digestion of chitosan (HMWC) and gel-filtration chromatography were analyzed by MALDI-TOF MS spectrometry.
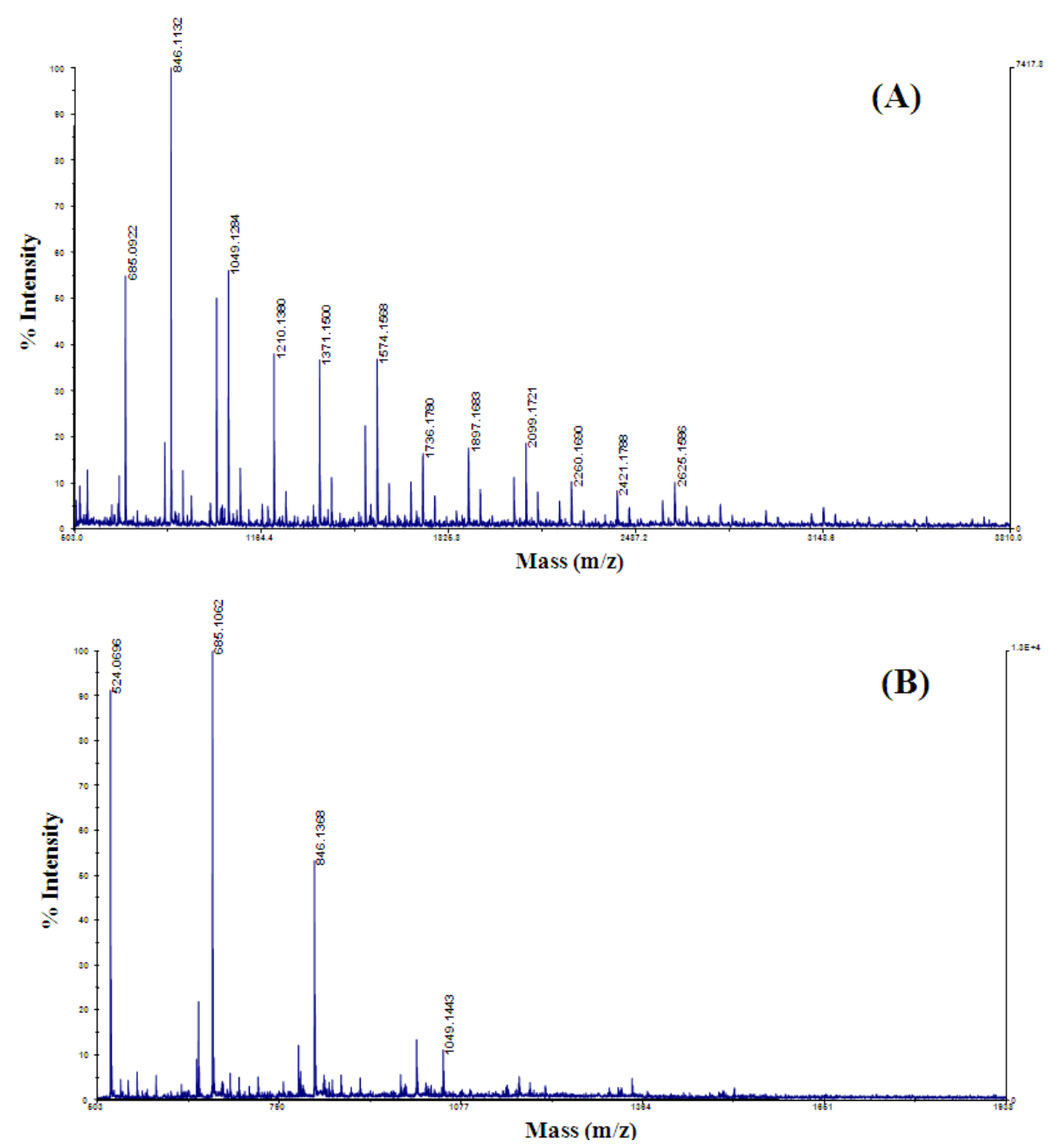
As shown in Figure $2 \mathrm{~B},(\mathrm{COS})_{\mathrm{n}}, \mathrm{n}=6$ was negligible in F-2; therefore, F-2 containing $(\mathrm{COS})_{\mathrm{n}}$, $\mathrm{n}=3-5$ and $\mathrm{F}-1$ containing $(\mathrm{HOS})_{\mathrm{n}}, \mathrm{n}=6-15$ as major component (Table 2) were used as pure chito-oligosaccharide or hetero-oligosaccharide mixtures without further separation to investigate the antitumor effect on human-derived tumor cells. Thus, the antitumor effects of HMWC, CTS-OS, $(\mathrm{COS})_{\mathrm{n}}, \mathrm{n}=3-5$ and $(\mathrm{HOS})_{\mathrm{n}}, \mathrm{n}=6-15$ on tumor cell lines were investigated to evaluate the relationship between the molecular weight and their DDA, as described in Tables 1 and 2, since no investigation was demonstrated in detail. The distribution of acetyl groups in the commercially available native chitosan is not evenly as in that produced by heterogeneous N-deacetylation of chitin. This is an interesting point for preparation of low molecular weight chitosan with different degrees of polymerization and DDA. Therefore, the preparation and characterization of the molecular weight and DDA of a series of CTS-OS precisely using MALDI-TOF MS gives rise to get better understanding of the relationship between biological functions of CTS-OS with different molecular weight and DDA.

Table 2. Prediction of the molecular weight of chitosan oligosaccharides (CTS-OS) by MALDI-TOF MS analysis.

\begin{tabular}{|c|c|}
\hline Chitosan oligosaccharides (CTS-OS) & $m / z$ \\
\hline$(\mathrm{GlcN})_{\mathrm{n}}, \mathrm{n}=2-5$ & $360,524,685,846$ \\
\hline$(\mathrm{GlcN})_{5}+\mathrm{GlcNAc}$ & 1049 \\
\hline $\begin{array}{l}(\mathrm{GlcN})_{5}+\mathrm{GlcNAc}+\mathrm{GlcN} \\
\text { Or }(\mathrm{GlcN})_{6}+\mathrm{GlcNAc}\end{array}$ & 1210 \\
\hline $\begin{array}{l}(\mathrm{GlcN})_{5}+\mathrm{GlcNAc}+(\mathrm{GlcN})_{2} \\
\text { Or }(\mathrm{GlcN})_{7}+\mathrm{GlcNAc}\end{array}$ & 1371 \\
\hline $\begin{array}{l}(\mathrm{GlcN})_{5}+\mathrm{GlcNAc}+(\mathrm{GlcN})_{2}+\mathrm{GlcNAc} \\
\text { or }(\mathrm{GlcN})_{7}+\mathrm{GlcNAc}\end{array}$ & 1574 \\
\hline $\begin{array}{l}(\mathrm{GlcN})_{5}+\mathrm{GlcNAc}+(\mathrm{GlcN})_{2}+\mathrm{GlcNAc}+\mathrm{GlcN} \\
\mathrm{Or}(\mathrm{GlcN})_{8}+(\mathrm{GlcNAc})_{2}\end{array}$ & 1735 \\
\hline $\begin{array}{l}(\mathrm{GlcN})_{5}+\mathrm{GlcNAc}+(\mathrm{GlcN})_{2}+\mathrm{GlcNAc}+(\mathrm{GlcN})_{2} \\
\operatorname{Or}(\mathrm{GlcN})_{9}+(\mathrm{GlcNAc})_{2}\end{array}$ & 1896 \\
\hline $\begin{array}{l}(\mathrm{GlcN})_{5}+\mathrm{GlcNAc}+(\mathrm{GlcN})_{2}+\mathrm{GlcNAc}+(\mathrm{GlcN})_{2}+\mathrm{GlcNAc} \\
\mathrm{Or}(\mathrm{GlcN})_{9}+(\mathrm{GlcNAc})_{3}\end{array}$ & 2099 \\
\hline $\begin{array}{l}(\mathrm{GlcN})_{5}+\mathrm{GlcNAc}+(\mathrm{GlcN})_{2}+\mathrm{GlcNAc}+(\mathrm{GlcN})_{2}+\mathrm{GlcNAc}+\mathrm{GlcN} \\
\mathrm{Or}(\mathrm{GlcN})_{10}+(\mathrm{GlcNAc})_{3}\end{array}$ & 2260 \\
\hline $\begin{array}{l}\mathrm{GlcN})_{5}+\mathrm{GlcNAc}+(\mathrm{GlcN})_{2}+\mathrm{GlcNAc}+(\mathrm{GlcN})_{2}+\mathrm{GlcNAc}+(\mathrm{GlcN})_{2} \\
\operatorname{Or}(\mathrm{GlcN})_{11}+(\mathrm{GlcNAc})_{3}\end{array}$ & 2421 \\
\hline $\begin{array}{l}\mathrm{GlcN})_{5}+\mathrm{GlcNAc}+(\mathrm{GlcN})_{2}+\mathrm{GlcNAc}+(\mathrm{GlcN})_{2}+\mathrm{GlcNAc}+(\mathrm{GlcN})_{2}+\mathrm{GlcNAc} \\
\mathrm{Or}(\mathrm{GlcN})_{11}+(\mathrm{GlcNAc})_{4}\end{array}$ & 2625 \\
\hline
\end{tabular}

\subsection{Antitumor Effect of High Molecular Weight Chitosan (HMWC)}

To examine the antitumor activity of HMWC, we carried out in vitro cytotoxicity experiments using MTT assay against human cells such as HepG2, A549, and PC3 as model tumor cell lines. Figure 3 shows the relative cell viability of these cells following $24 \mathrm{~h}$ incubation with PBS as the control or a wide range of concentrations of HMWC with from 0.75 to $50 \mu \mathrm{g} \cdot \mathrm{mL}^{-1}$. While PBS alone did not show any appreciable toxicity, HMWC showed significantly higher cytotoxicity toward human HepG2 and 
A549 than PC3 cells, with $\mathrm{IC}_{50}$ values lower than $50 \mu \mathrm{g} \cdot \mathrm{mL}^{-1}$. These results demonstrated that HMWC has antitumor activities against various tumor cell lines in vitro and is applicable as an antitumor agent based on the biodegradability and biocompatibility of HMWC, although the antitumor mechanism is not clear yet. Chitosan with different molecular weights and DDA are implicated to exhibit growth inhibitory effects against tumors in experimental animals, though the antitumor activity of chitosan seems to depend not only on molecular size but also on their chemical structure.

Figure 3. Effect of high molecular weight chitosan (HMWC) on human tumor cell lines. Cytotoxicity of HMWC against human tumor cells was performed using MTT assay in

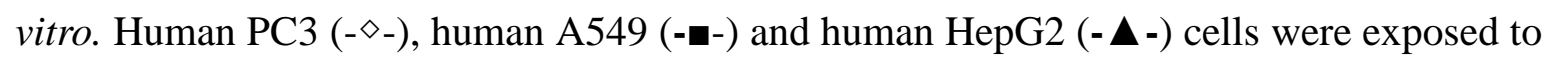
the indicated amounts of chitosan for $24 \mathrm{~h}$. After $24 \mathrm{~h}$ incubation, the absorbance of the solution was measured at $575 \mathrm{~nm}$ using a micro-plate reader. Data are the means \pm standard deviation of three different experiments. The statistical significance of the difference between mean values was determined by the student's t-test. $* \mathrm{P}<0.05$ and $* * \mathrm{P}<0.1$ was considered significant. Experiments were performed at least in triplicates.

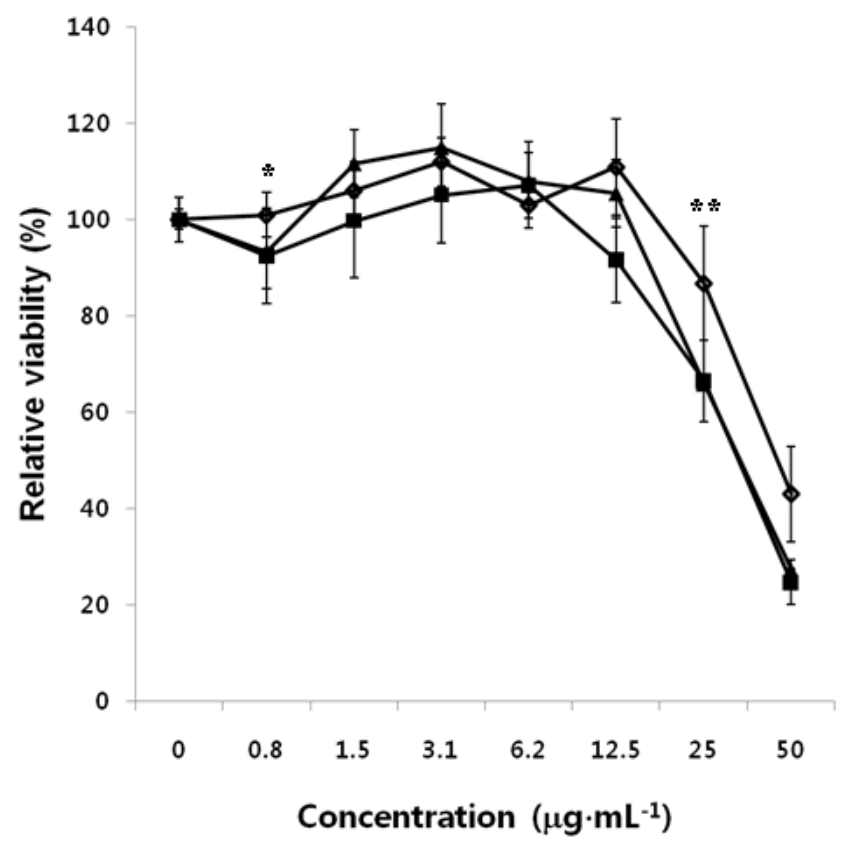

\subsection{Antitumor Effect of HMWC, CTS-OS, COS and HOS on Human PC3 Cells}

The antitumor effects of CTS-OS, COS and HOS on human PC3 cells were evaluated in vitro cytotoxicity experiment with a wide range of concentrations from 0.75 to $50 \mu \mathrm{g} \cdot \mathrm{mL}^{-1}$, as described above. Figure 4 shows that CTS-OS showed the strongest effect against human PC3 cells used as a model cell line, with $\mathrm{CC}_{50}$ values of $25 \mu \mathrm{g} \cdot \mathrm{mL}^{-1}$. Treatment of COS could inhibit tumor growth similar to that of CTS-OS In contrast, as shown in Figure 3, HOS showed slightly less growth inhibition of tumor cells with the $50 \%$ cytotoxic concentration $\left(\mathrm{CC}_{50}\right)$ values of $50 \mu \mathrm{g} \cdot \mathrm{mL}^{-1}$. Compared to HMWC, HOS showed no apparent difference in antitumor activity, though native chitosan and HOS have different extent of sizes of molecular weight. Therefore, DDA is considered as a principal features of HMWC, CTS-OS and COS. Unlike HMWC, both CTS-OS and COS attract greater interest as antitumor agents due to their water solubility. 
Figure 4. Effect of HMWC, CTS-OS, COS and HOS on human PC3 cells. Cells were exposed to the indicated amounts of HMWC (-X-), CTS-OS (-m-), HOS (-^-), and COS (- $\boldsymbol{\Delta}$-) for $24 \mathrm{~h}$. After $24 \mathrm{~h}$ incubation, cytotoxicity of CTS-OS, COS and HOS against tumor cells was determined by MTT assay. Data are mean values calculated from three independent experiments $( \pm \mathrm{SD})$. $* \mathrm{P}<0.05$ and $* * \mathrm{P}<0.1$ was considered significant.

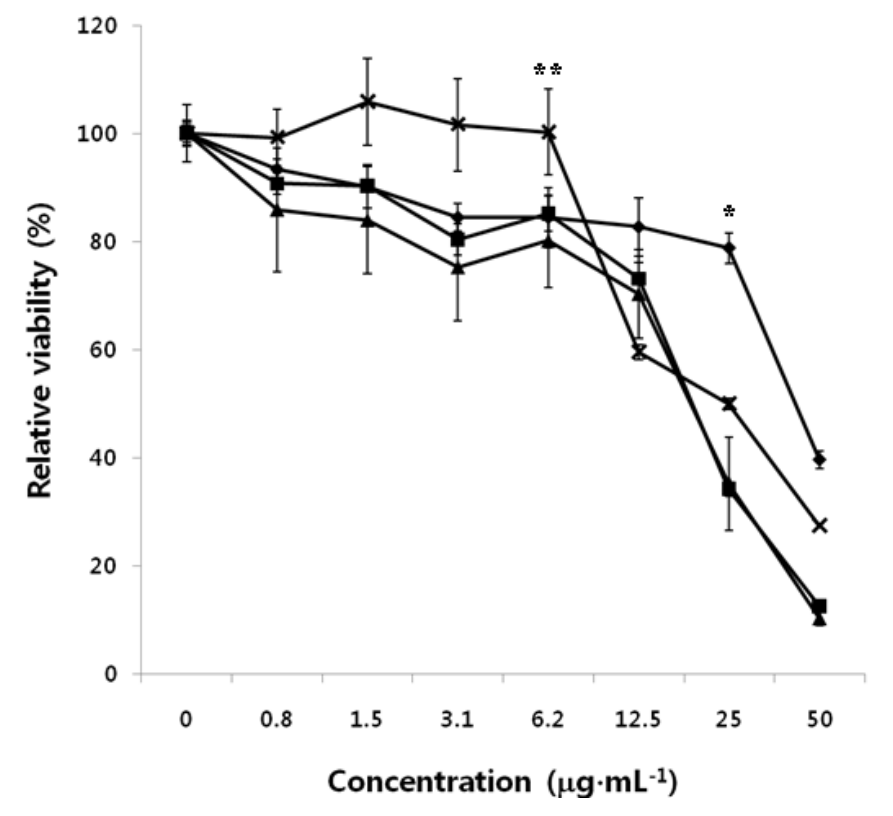

\subsection{Antitumor Effect of HMWC, CTS-OS, COS and HOS on Human A549 Cells}

The results showed that antitumor effects of CTS-OS, COS and HOS on human A549 cells were observed from in vitro cytotoxicity experiment with a wide range of concentrations from 0.75 to $50 \mu \mathrm{g} \cdot \mathrm{mL}^{-1}$, as described above. Figure 5 shows that CTS-OS, which consists of COS and HOS, displayed the strongest effect toward A549 cells with $\mathrm{CC}_{50}$ values of $25 \mu \mathrm{g} \cdot \mathrm{mL}^{-1}$. Treatment of COS could inhibit tumor growth similar to that observed by CTS-OS as well. On the other hand, HOS showed much low activity against tumor cells with $\mathrm{CC}_{50}$ values higher than $50 \mu \mathrm{g} \cdot \mathrm{mL}^{-1}$. No apparent difference of the antitumor activity of HOS compared to that of HMWC was observed.

\subsection{Antitumor Effect of HMWC, CTS-OS, COS and HOS on Human HepG2 Cells}

The antitumor effects of CTS-OS, COS and HOS on human HepG2 cells were evaluated in vitro cytotoxicity experiments with a wide range of concentrations from 0.75 to $50 \mu \mathrm{g} \cdot \mathrm{mL}^{-1}$. The results showed that CTS-OS has the strongest effect against HepG2 cells with $\mathrm{CC}_{50}$ values lower than $25 \mu \mathrm{g} \cdot \mathrm{mL}^{-1}$ (Figure 6). Treatment of a series of CTS-OS COS and HOS on HepG2 cells resulted in apparent toxicity compared with the other cell lines, A549 and PC3 cells (Figures 4 and 5). These results suggest that chitosan oligosaccharides have higher specificity toward human HepG2 cells, while there was slightly increased $(<15 \%)$ relative cell viability to both cells A549 and PC3 cells. On the other hand, treatment of COS could inhibit tumor growth similar to the relative cell viability of all three cells exposed to CTS-OS at the same concentration. As expected, HOS showed much less tumor cell growth inhibition with $\mathrm{CC}_{50}$ values higher than $50 \mu \mathrm{g} \cdot \mathrm{mL}^{-1}$. However, compared to HMWC, HOS showed similar antitumor activity. 
Figure 5. Effect of HMWC, CTS-OS, COS and HOS on human A549 cells. Cells were exposed to the indicated amounts of HMWC (-X-), CTS-OS (-m-), HOS (-•-), and COS (- $\mathbf{\Delta}$-) for $24 \mathrm{~h}$. After $24 \mathrm{~h}$ incubation, cytotoxicity of CTS-OS, COS and HOS against tumor cells was determined by MTT assay. Data are mean values calculated from three independent experiments $( \pm \mathrm{SD})$. $* \mathrm{P}<0.05$ and $* * \mathrm{P}<0.1$ was considered significant.

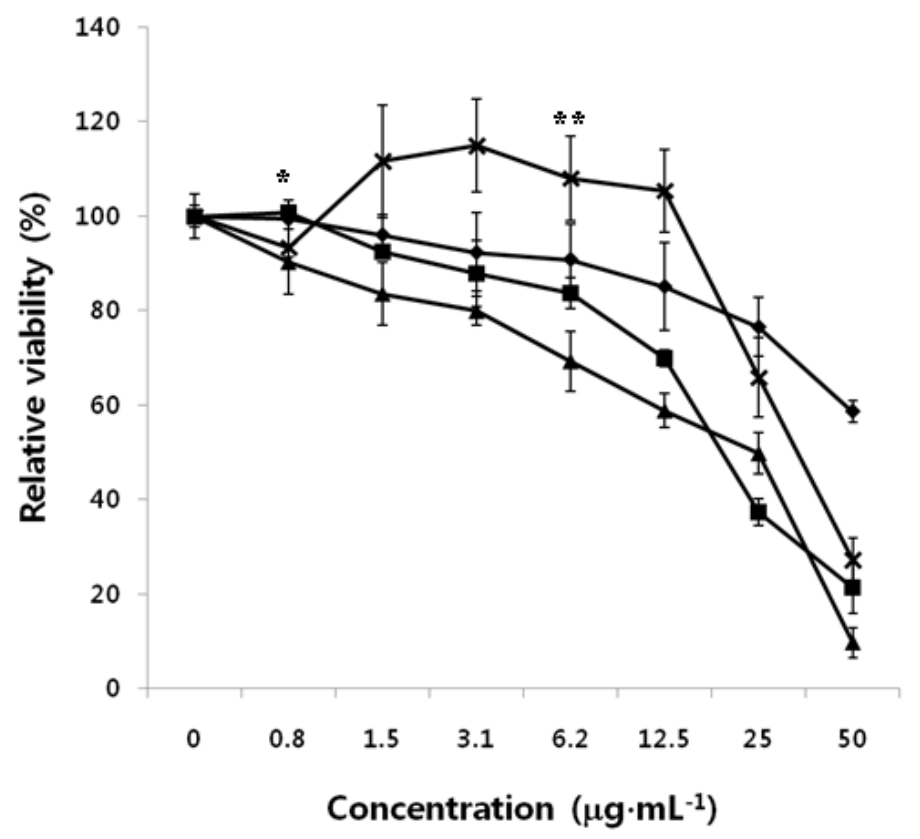

Figure 6. Effect of HMWC, CTS-OS, COS and HOS on human HepG2 cells. HepG2 cells were exposed to the indicated amounts of HMWC (-X-), CTS-OS (-m-), HOS (-^-), and

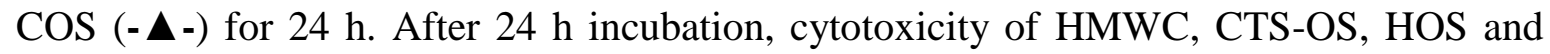
COS against tumor cells was examined by MTT assay. Data expressed are the means $( \pm \mathrm{SD})$ of three different experiments. ${ }^{*} \mathrm{P}<0.05$ and $* \mathrm{P}<0.1$ was considered significant.

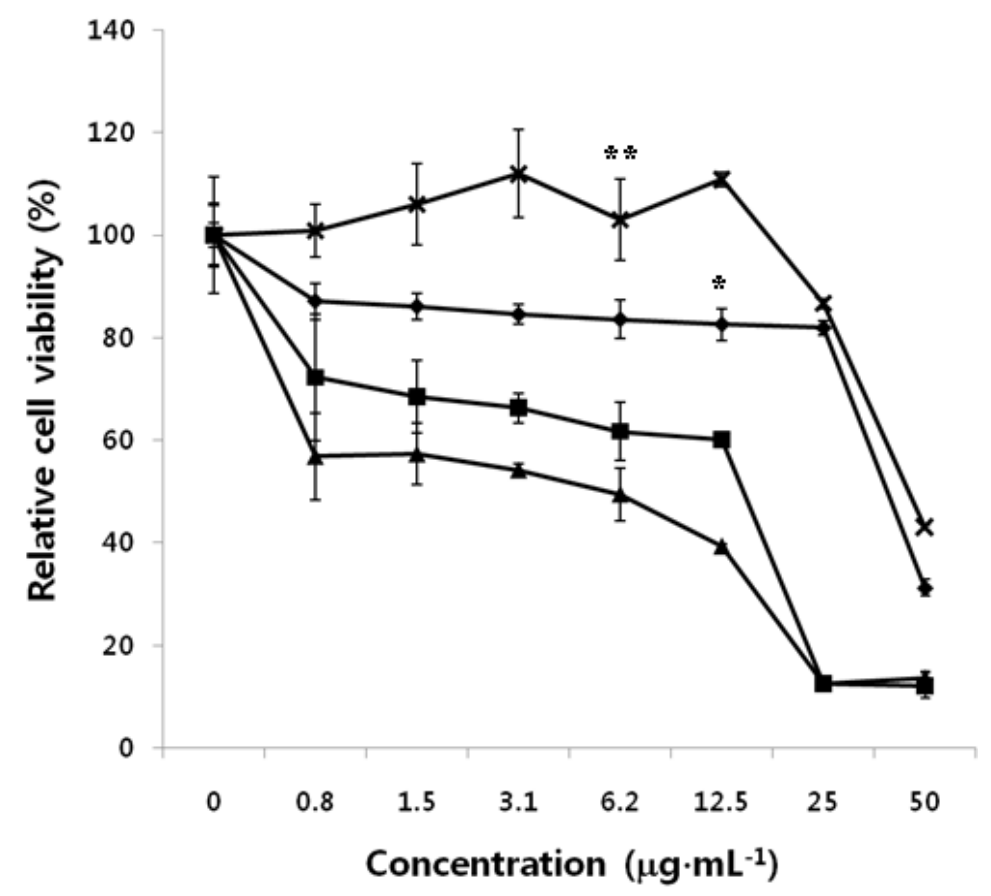


The functional properties of chitosan and its depolymerized compounds are mainly dependent upon their solubility, molecular weight and DDA in aqueous media. To overcome these problems, preparation of chitosan oligosaccharides in an active form is obviously gaining importance in many biomedical applications. Although several methods are available for the preparation of oligomeric compounds, development of new effective methods for producing biologically active molecules from chitosan is a major challenge in carbohydrate chemistry to provide sufficient amounts of products needed for fundamental research and their potential application in various fields. Therefore, the main objective of the present study was to evaluate the structural characteristics such as molecular weight and DDA of COS and HOS obtained from the enzymatic hydrolysis of HMWC, and their antitumor activity toward human tumor cells was tested in this study. The results clearly demonstrated that the molecular weight and DDA of chitosan oligosaccharides are important factors for their antitumor activities (Table 3). The relatively smaller size (molecular weight), higher solubility, and the lower degree of deacetylation (DDA) of CTS-OS and COS than HMWC would be promising factors for the development of potential pharmaceuticals or neutraceuticals using these chitosan derivatives.

Table 3. Effect of the degree of deacetylation (DDA) of chitosan derivatives on antitumor activity.

\begin{tabular}{|c|c|c|c|c|}
\hline \multirow{2}{*}{ Samples } & \multirow{2}{*}{ DDA (\%) } & \multicolumn{3}{|c|}{$\mathbf{C C}_{\mathbf{5 0}}\left(\boldsymbol{\mu g} \cdot \mathbf{m L}^{-\mathbf{1}}\right)^{*}$} \\
\cline { 3 - 5 } & & $\mathbf{P C 3}$ & $\mathbf{A 5 4 9}$ & HepG2 \\
\hline HMWC & 98.5 & 50 & 50 & 50 \\
\hline CTS-OS & 98.5 & 25 & 25 & 25 \\
\hline COS & 100 & 25 & 5 & 12.5 \\
\hline HOS & 85.5 & 50 & 50 & 50 \\
\hline
\end{tabular}

$* \mathrm{CC}_{50}\left(\mu \mathrm{g} \cdot \mathrm{mL}^{-1}\right)$ the concentration of each sample required for $50 \%$ cell death.

\section{Experimental Section}

\subsection{Materials}

A high molecular weight of chitosan (HMWC) with approximately $1,900 \mathrm{kDa}, 98.5 \%$ degree of deacetylation (DDA) was kindly provided by Prof. R. D. Park, Cheonnam University, Korea. A recombinant chitosanase (OHK) was purchased from Kyowa Chemical Ltd. (Japan). All other reagents were used without further purification and were of the highest grade available.

\subsection{Tumor Cell-Lines}

Human PC3 (prostate cancer cell, ATCC No. CRL-1435 ${ }^{\mathrm{TM}}$ ), A549 (carcinomic human alveolar basal epithelial cell, ATCC No. CCL-185 ${ }^{\mathrm{TM}}$ ) and HepG2 (hepatocellular carcinoma cell, ATCC No. HB- $8065^{\mathrm{TM}}$ ) cells are used as the first choice for evaluating the antitumor effects of chitosan and its oligosaccharides in vitro. Cells were grown and maintained in Roswell Park Memorial Institute medium (RPMI) 1640 supplemented with 10\% (v/v) heat-inactivated fetal bovine serum (FBS) and 1\% penicillin-streptomycin (GIBCO, USA). The cells were maintained at $37{ }^{\circ} \mathrm{C}$ under $5 \% \mathrm{CO}_{2}$. 


\subsection{Preparation of Chitosan-Oligosaccharides}

The high molecular weight chitosan (HMWC) was fully dissolved in $1 \%$ acetic acid to be $1 \%$ (w/v) at room temperature and the $\mathrm{pH}$ of the solution was adjusted to $\mathrm{pH} 5.0$ with $\mathrm{NaHCO}_{3}$. The chitosan solution was centrifuged at $14,000 \mathrm{rpm}$ for $30 \mathrm{~min}$ to remove insoluble materials. Then chitosan was hydrolyzed at $30{ }^{\circ} \mathrm{C}$ for $2 \mathrm{~h}$ using $0.5 \mathrm{U}$ (nmol reducing sugars $/ \mu \mathrm{g} / \mathrm{min}$ ) of recombinant chitosanase OHK purchased from Kyowa Chemical Ltd., and the reactant was boiled to quench the reaction at $100{ }^{\circ} \mathrm{C}$ for $10 \mathrm{~min}$. Following, an ultra-filtration membrane filter with molecular weight cut off (MWCO) of $10 \mathrm{kDa}$ was used to remove denatured protein, insoluble materials and separate water-soluble chitosan-oligosaccharides CTS-OS. Obtained CTS-OS was further free-dried, and kept at $4{ }^{\circ} \mathrm{C}$ until use. For cytotoxicity test against tumor cells, solutions (1\% acetic acid) of HMWC and its enzyme hydrolyzed products (CTS-OS, HOS, and COS) were adjusted to $\mathrm{pH} 5.0$ with $1 \mathrm{M} \mathrm{NaHCO}_{3}$ and then applied to each tumor cell culture.

\subsection{Gel-filtration Chromatography}

CTS-OS obtained after digestion of HMWC was further fractionated using a gel-filtration column chromatograph $(\Phi 1.0 \mathrm{~cm} \times \mathrm{L} 30 \mathrm{~cm}$ ) packed with Bio Gel-P 4 (Bio-RAD, USA) gel, which had been pre-equilibrated with a volatile buffer consisting of ammonia/formic acid ( $\mathrm{pH} 7.5$ ). A total of $500 \mathrm{mg}$ CTS-OS dissolved in $1.0 \mathrm{~mL}$ of the same buffer was applied to a gel-filtration column and eluted at a flow-rate of $5 \mu \mathrm{L}$ per min until no carbohydrates were detected using the Nelson-Somogyi method [17].

\subsection{Determination of Molecular Weight and Deacetylation Degree (DDA) of CTS-OS by MALDI-TOF} MS Analysis

The two major carbohydrate-positive fractions obtained were applied to matrix-assisted laser desorption/ionization-time of flight mass spectrometry (MALDI-TOF MS) analysis. The molecular weight and deacetylation degree (DDA) of CTS-OS obtained from the enzymatic hydrolysis of chitosan was determined by matrix-assisted laser desorption/ionization-mass spectrometry (MALDI-TOF MS) analysis (Voyager-DE TM STR Biospectrometry Workstation, Applied Biosystems Inc., NCIRF, Korea). The molecular weight and DDA of CTS-OS was calculated based on the molecular weight of glucosamine $(\mathrm{GlcN})$ and $N$-acetylglucosamine (GlcNAc).

\subsection{Cytotoxicity against Tumor Cells in Vitro}

The viability of tumor cell lines PC3, A549, and HepG2 human-derived against HMWC and its oligosaccharides was determined by the 3-(4,5-dimethylthiazol-2-yl)-2,5-diphenyl tetrazolium bromide (MTT, Sigma) reduction assay [18]. Tumor cells were placed in RPMI 1640 supplemented with $10 \%$ FBS (PAA) and $1 \%$ penicillin-streptomycin (GIBCO) at $1 \times 10^{4}$ cells/well in 24-well culture plates. After, the cells were cultured overnight at $30{ }^{\circ} \mathrm{C}$, and the medium was changed to fresh RPMI 1640. Then cells were exposed to the indicated amounts of chitosan and its oligosaccharides for $24 \mathrm{~h}$. After monolayer cultivation for $24 \mathrm{~h}$, the medium was removed and $100 \mu \mathrm{L}$ of the maintenance medium (MM) and different concentrations of samples were added to each well and the samples were then incubated for an additional $24 \mathrm{~h}$. After $24 \mathrm{~h}$ incubation, $20 \mu \mathrm{L}$ of MTT ((3,4,5-dimetylthiazol-2-yl)-2,5- 
diphenyl tetrazonium bromide)) solution $\left(5 \mathrm{mg} \cdot \mathrm{mL}^{-1}\right)$ was added to each well of the plate and re-incubated for $4 \mathrm{~h}$. After removal of the supernatant, $100 \mu \mathrm{L}$ of DMSO were added to each well to dissolve the crystals completely and the absorbance was measured at $570 \mathrm{~nm}$ using an ELISA Reader (Bio-Rad, USA). The cytotoxicity was expressed as the $50 \%$ cytotoxic concentration $\left(\mathrm{CC}_{50}\right)$, the concentration of samples needed to inhibit the cell growth by $50 \%$.

\subsection{Statistical Analysis}

All data were expressed as the means \pm standard Deviation (SD), which are representative of at least three different experiments. Comparison between individual data points of each experiment were conducted using Student's $t$-test. All $p$-values of $<0.1$ were considered to be significant.

\section{Conclusions}

In the present study, we report antitumor effects of HMWC, CTS-OS, COS and HOS toward three different human tumor cell lines used as a model for the experiments in vitro. Our results show that, among other compounds, CTS-OS and COS obtained from enzymatic hydrolysis of chitosan and identified by MALDI-TOF MS analysis showed significant antitumor activities against human A549, PC3, and HepG2 tumor cells. More importantly, no significant antitumor effect of HMWC and HOS was observed. Taken together, these results strongly suggest that properties of chitosan, such as the average molecular weight and the degree of $N$-deacetylation (DDA), might be important factors for the exhibition of antitumor activity in vitro. Since CTS-OS and COS have higher solubility in water and narrow molecular weight distribution ensuring reproducible pharmacological properties compared to HOS and HMWC, they may provide valuable information for the further development of antitumor agents deriving from chitosan.

\section{Acknowledgments}

This work was supported by a grant from the Gyeonggi-do GRRC program of the Catholic University of Korea and partly the grant from the Small \& Medium Business Administration (SMBA, 2101MF-01-00117-A-0002), Republic of Korea, for which the authors are thankful.

\section{References}

1. Harish Prashanth, K.V.; Tharanathan, R.N. Depolymerized products of chitosan as potent inhibitors of tumor-induced angiogenesis. Biochim. Biophys. Acta 2005, 1722, 22-29.

2. Maeda, Y.; Kimura, Y. Antitumor effects of various low-molecular-weight chitosans are due to increased natural killer activity of intestinal intraepithelial lymphocytes in sarcoma 180-bearing mice. J. Nutr. 2004, 134, 945-950.

3. Qin, C.; Du, Y.; Xiao, L.; Li, Z.; Gao, X. Enzymic preparation of water-soluble chitosan and their antitumor activity. Int. J. Biol. Macromol. 2002, 31, 111-117.

4. Wang, S.L.; Lin, H.T.; Liang, T.W.; Chen, Y.J.; Yen, Y.H.; Guo, S.P. Reclamation of chitinous materials by bromelain for the preparation of antitumor and antifungal materials. Bioresour. Technol. 2008, 99, 4386-4393. 
5. Yamada, S.; Ganno, T.; Ohara, N.; Hayashi, Y. Chitosan monomer accelerates alkaline phosphatase activity on human osteoblastic cells under hypofunctional conditions. J. Biomed. Mater. Res. A 2007, 83, 290-295.

6. Gunbeyaz, M.; Faraji, A.; Ozkul, A.; Purali, N.; Senel, S. Chitosan based delivery systems for mucosal immunization against bovine herpesvirus 1 (BHV-1). Eur. J. Pharm. Sci. 2010, 41, 531-545.

7. Xia, W.; Liu, P.; Liu, J. Advance in chitosan hydrolysis by non-specific cellulases. Bioresour. Technol. 2008, 99, 6751-6762.

8. Kumar, B.A.; Varadaraj, M.C.; Tharanathan, R.N. Low molecular weight chitosan--preparation with the aid of pepsin, characterization, and its bactericidal activity. Biomacromolecules 2007, 8 , $566-572$.

9. Nanjo, F.; Katsumi, R.; Sakai, K. Enzymatic method for determination of the degree of deacetylation of chitosan. Anal. Biochem. 1991, 193, 164-167.

10. Zheng, Y.; Yi, Y.; Qi, Y.; Wang, Y.; Zhang, W.; Du, M. Preparation of chitosan-copper complexes and their antitumor activity. Bioorg. Med. Chem. Lett. 2006, 16, 4127-4129.

11. Ruel-Gariepy, E.; Shive, M.; Bichara, A.; Berrada, M.; Le Garrec, D.; Chenite, A.; Leroux, J.C. A thermosensitive chitosan-based hydrogel for the local delivery of paclitaxel. Eur. J. Pharm. Biopharm. 2004, 57, 53-63.

12. Sato, M.; Onishi, H.; Takahara, J.; Machida, Y.; Nagai, T. In vivo drug release and antitumor characteristics of water-soluble conjugates of mitomycin $\mathrm{C}$ with glycol-chitosan and $\mathrm{N}$-succinylchitosan. Biol. Pharm. Bull. 1996, 19, 1170-1177.

13. Seo, S.H.; Han, H.D.; Noh, K.H.; Kim, T.W.; Son, S.W. Chitosan hydrogel containing GMCSF and a cancer drug exerts synergistic anti-tumor effects via the induction of CD8+ T cell-mediated anti-tumor immunity. Clin. Exp. Metastasis 2009, 26, 179-187.

14. Song, Y.; Onishi, H.; Nagai, T. Pharmacokinetic characteristics and antitumor activity of the $\mathrm{N}$-succinyl-chitosan-mitomycin $\mathrm{C}$ conjugate and the carboxymethyl-chitin-mitomycin C conjugate. Biol. Pharm. Bull. 1993, 16, 48-54.

15. Zhang, J.; Chen, X.G.; Liu, C.S.; Park, H.J. Investigation of polymeric amphiphilic nanoparticles as antitumor drug carriers. J. Mater. Sci. Mater Med. 2009, 20, 991-999.

16. $\mathrm{Xu}, \mathrm{Y}$; Wen, Z.; $\mathrm{Xu}, \mathrm{Z}$. Chitosan nanoparticles inhibit the growth of human hepatocellular carcinoma xenografts through an antiangiogenic mechanism. Anticancer Res. 2009, 29, 5103-5109.

17. Smogyi, M. Notes on sugar determination. J. Biol. Chem. 1952, 195, 19-23.

18. Ngamwongsatit, P.; Banada, P.P.; Panbangred, W.; Bhunia, A.K. WST-1-based cell cytotoxicity assay as a substitute for MTT-based assay for rapid detection of toxigenic Bacillus species using CHO cell line. J. Microbiol. Methods 2008, 73, 211-215.

(C) 2011 by the authors; licensee MDPI, Basel, Switzerland. This article is an open access article distributed under the terms and conditions of the Creative Commons Attribution license (http://creativecommons.org/licenses/by/3.0/). 